\title{
REPORTING A RARE CASE OF WITKOP'S TOOTH AND NAIL SYNDROME (TNS) - A CLINICAL VIEW
}

\section{Mamta Dali}

\begin{abstract}
Witkop's syndrome, a gentle form of ectodermal dysplasia, is a rare autosomal dominant disease manifested by defects of the nail plates of the fingers and toes, hypodontia or anodontia with normal hair and sweat gland function. Other ectodermal tissues, organs do not show any alteration. Oral manifestations may include incomplete development of both primary and permanent tooth germs. The location and form of erupted teeth could be irregular. This paper reports a rare case of Witkop tooth and nail syndrome (TNS) presenting a typical clinical features of this syndrome and discusses various dental treatment modalities available.
\end{abstract}

Key Words: Dental treatment, Hypodontia, Tooth and nail syndrome, Witkop syndrome

\section{Introduction}

Witkop's syndrome (a gentle form of ectodermal dysplasia), a rare autosomal dominantly inherited developmental ectodermal tissue anomaly, manifesting in defects of the nail plates of the fingers and toes, and in hypodontia or anodontia with normal hair and sweat gland function..$^{[1,2]}$

In 1965, Witkop, a dermatologist, observed patients with tooth and nail problems, which occurred commonly in the Dutch Mennonites of Canada. This condition differed from hypohidrotic forms of ectodermal dysplasia in that affected persons did not have involvement of ectodermally derived glands (sweat gland) and the hair, and was normal in distribution. He termed this syndrome as "tooth and nail" type of autosomal dominant ectodermal dysplasia. ${ }^{[3]}$

Typically, toenails are more severely affected than fingernails, and in some instances, nail plates are absent at birth. ${ }^{[4]}$ Fingernails and toenails may be poorly developed, abnormally small, ridged, spoon shaped, brittle, and slow to grow. Rarely, the nails separate from the nail beds and fall off. Occasionally, sparse scalp hair is observed .People with TNS may have absent, widely spaced, or cone-shaped teeth with narrow crowns. The teeth that are most commonly missing in this condition include the incisors and the canines of the upper jaw and the second molars. This syndrome affects both primary (deciduous) and permanent teeth. While the primary teeth are often normal, the condition is often suspected when secondary teeth fail to come in.

This paper presents a case which appears, to our best knowledge, very unusual and rare due to the total absence of the permanent dentition along with the defects of fingernails and toenails.

\section{Case Report}

A 10-year-old male patient was refered to the Department Dentistry, because of missing teeth on maxillary arch and spacing between teeth in mandibular arch. Clinical examination revealed that intraorally there was presence of retained conical shaped maxillary and mandibular incisors with missing maxillary both central incisors along 
with presence of complete set of other remaining primary teeth (Fig1).

Fig 1: Clinical photograph showing conical shaped deciduous maxillary and mandibular incisors.

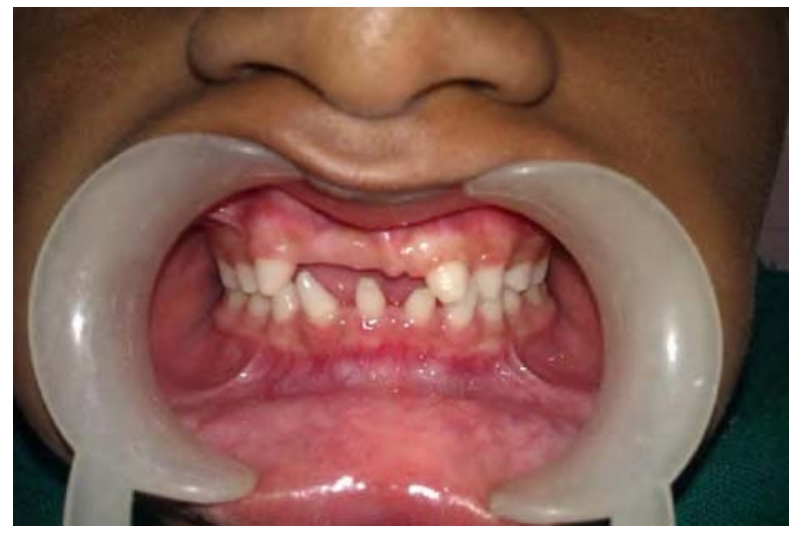

Dentition was characterized with generalized spacing and microdontia with cone shaped incisors on mandibular arch. The oral hygiene was good with no clinically visible caries and the gingival tissues appeared healthy. Extraoral examination revealed concave profile with hypoplastic maxilla and a relative prognathic mandible (Fig 2a). Fig 2a: Facial Profile showing relative prognathic mandible

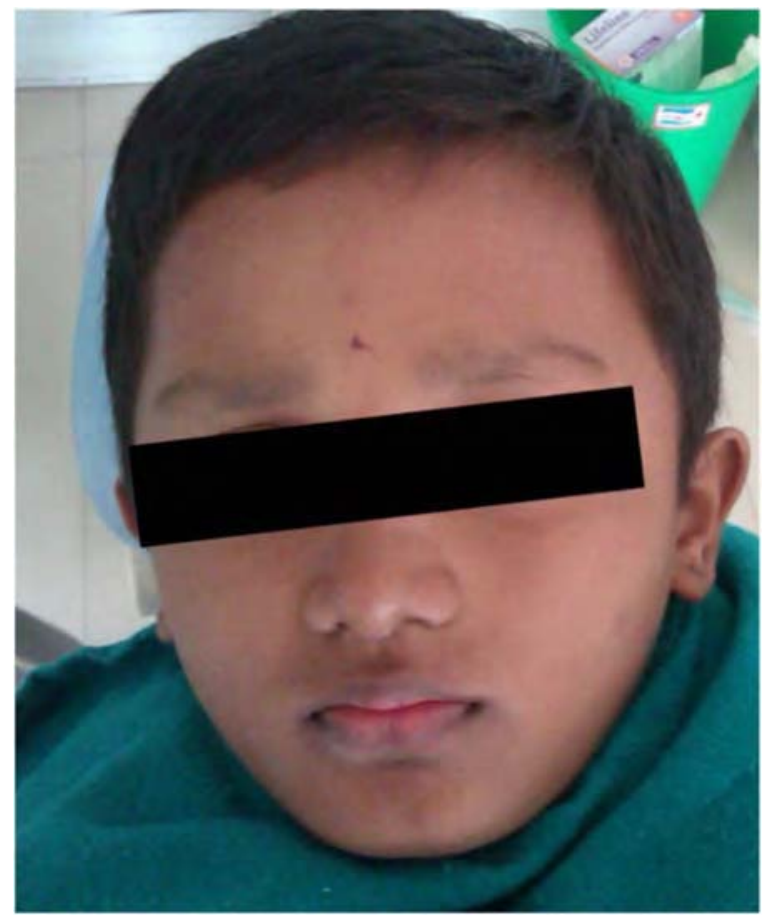

Physical examinations revealed the changes in fingernails and toenails, especially dysplasia, koilonychia of fingernails and onychorrhexis of the toenails, which were prone to fragility were noted (Fig.3a, 3b). Fig 3a, 3b: Koilonychia of fingernails and onychorrhexis of the toenails


The patient's family was evaluated regarding potential clinical features. The child was born to nonconsanguineous parents and there was no any history of similar features or any severe systemic diseases in the family. Radiographic examination in orthopantomogram (OPG) revealed erupted complete set of primary teeth with missing maxillary both central incisor and right lateral incisor and complete absence of permanent tooth buds (Fig 4).

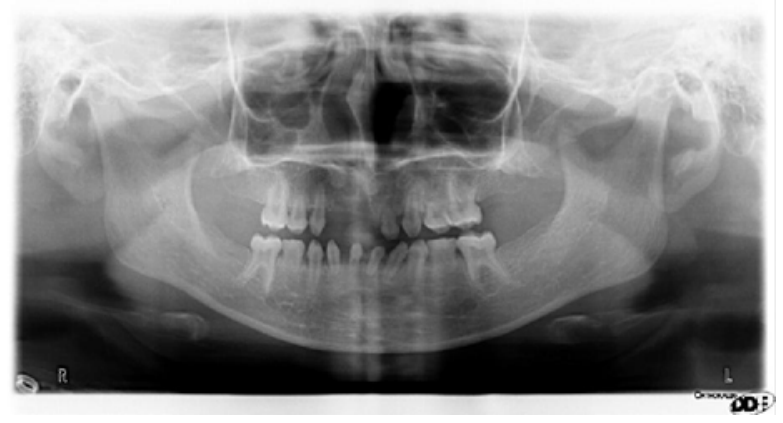


Surprisingly, tooth roots of the deciduous teeth were still present without any features of resorption. According to the past dental history given by the patient's mother, there was physiologic exfoliation of primary maxillary both central incisor and the permanent teeth did not erupt after the shedding in the maxillary anterior region. Though there was absence of such findings in family members, based on clinical and radiological examinations, a diagnosis of wiktop's tooth and nail syndrome (TNS) was made. The line of treatment planned for the above reported case was to restore the missing maxillary right incisor with removable partial prosthetic appliance as our patient was in adolescent age group. The patient is to be monitored every six months to determine the need to refit or remake of removable partial prosthetic appliance. Implants and fixed prosthesis are recommended later in life after the complete growth of the jaw bones.

\section{Discussion}

Only a few reports have been published regarding tooth and nail syndrome (Witkop syndrome) which is an autosomal dominant hereditary disorder meaning that it is caused by a single copy of the responsible gene that is usually inherited from a parent who is also affected by the disease. Both males and females may develop this syndrome which is characterized primarily by teeth and nail deformities deriving from the ectoderm. Other types of ectodermal dysplasia involving the teeth and nails are Fried TNS, deafness and onychoosteodystrophy with retardation (DOOR syndrome) and Curry-Hall syndrome. The diagnosis of TNS may be suspected at birth if one or more toe- or fingernails are absent. However, the disorder is more often detected at approximately 4 or 5 years of age, when the absence of some primary teeth and/or hypoplasia of nails is noted. The range of hypodontia in TNS reported in the published literature has varied from one or two missing teeth to severe hypodontia. ${ }^{[5,6]}$ In TNS, the absence of second molars, mandibular incisors, and maxillary canines has been most often reported. ${ }^{[7,8]}$ However, in our case the patient demonstrated no permanent dentition at all.

A genetic test may be performed to confirm a diagnosis. The gene responsible for Witkop TNS was identified in 2001 and is termed MSX1. ${ }^{[9]}$ This gene is recognized as important in tooth formation, and the mutation that results in Witkop TNS appears to encode a protein that is completely nonfunctional. If there is a family history of HND, prenatal testing may be performed to determine whether the fetus has the disorder.

The quality of life of the affected individuals can be improved by an interdisciplinary approach of the treatment plan. Prosthetic treatment may include removable, fixed, implant-supported prostheses, or a combination of these options. ${ }^{[10,11]}$ For the rehabilitation, it is crucial to know the age, number and condition of the present teeth, alveolar ridges and the growth status of the patient. The type of dental treatment depends on the severity of the disease (tooth size, tooth stability, and amount of available alveolar bone). Removable partial dentures can be used to replace congenitally missing teeth, and composite resin materials can be applied to restore conical-shaped maxillary teeth to achieve a favorable esthetic result. These options minimize the sacrifice of healthy dental tissues. ${ }^{[12]}$ In our case fabrication of the removable partial denture was planned for maxillary arch followed by fixed prosthesis in future after the completion of the jaw growth. Therefore, a comprehensive approach to TNS should include not only the assessment of oral/dental manifestations but also this newly described general clinical feature. 


\section{Conc usion}

Witkop's syndrome, or tooth and nail syndrome, is an autosomal dominant condition with hypodontia and teeth with conical crowns, with a nail dysplasia which is present from birth and improves with age. A multidisciplinary approach that includes pedodontics, orthodontics and prosthetic therapy is often necessary for dental management of young TNS patients. Considering the level of complexity in the management of these patients, treatment should begin with early diagnosis to prevent future functional and aesthetic problems.

\section{References}

1. Martin JW, Tse ios N, Chambers MS. Treatment strategy for patients with ectodermal dysplasia: a case report. J Clin Pediatr Dent. 2005; 29:113-118.

2. Hickey A J, Vergo TJ Jr. Prosthetic treatments for patients with ectodermal dysplasia. J Prosthet Dent. 2001;86:364-36

3. Witkop CJ. Genetic diseases of the oral cavity. In: Tiecke RW, ed. Oral pathology. New York: McGraw-Hill Book Company, 1965:786-843.

4. Hudson CD, Witkop CJ Jr.. Autosomal dominant hypodontia with nail dysgenesis. Oral Surg 1975;39:409-423.
5. Witkop CJ, Tiecke RW Jr. Genetic diseases of the oral cavity. Oral Pathology 1965;15: 810-4.

6. A tug-Atac AT, Iseri H. Witkop tooth and nail syndrome and orthodontics. Angle Orthod. 2008:Mar;78(2):370-80.

7. Devadas S, Varma B, Mungara J, Joseph T, Saraswathi TR. Witkop tooth and nail syndrome: a case report. Int J Paediatr Dent. 2005 Sep;15(5):364-9.

8. Wicomb GM, Stephen LX, Beighton P. Dental implications of Tooth-Nail dysplasia (Witkop syndrome): a report of an affected family and an approach to dental management. J Clin Pediatr Dent. 2004 Winter;28(2):107-12.

9. Jum ongras D, Bei M, Stimson JM, et a . A nonsense mutation in MSX1 causes Witkop syndrome. Am J Hum Genet. 2001;69:67-74.

10. Rashedi B. Prosthodontic treatment with implant fixed prosthesis for a patient with ectodermal dysplasia: a clinical report. J Prosthodont 2003; 12:198-201.

11. Guckes AD, Brahim JS, McCarthy GR, Rudy SF, Cooper LF. Using endosseous dental implants for patients with ectodermal dysplasia. J Am Dent Assoc 1991; 122:59-62.

12. Vivien TS, Thais MO, Ju iano PP, Car os FS, Maria AA. Alternative oral rehabilitation of children with hypodontia and conical tooth shape: a clinical report. Quintessence Int 2006; 37:725730 .

Address of Correspondence: Dr. Mamta Dali, Lecturer, Department of Pedodontics and Preventive Dentistry, Nobel Medical and Dental College and Teaching Hospital Pv.t Ltd., Nepal. 